\title{
Analyzing Capabilities And Enterprise Strategy: A Value Proposition Framework
}

Leslie Leong, University of Greenwich, England

A.T. Jarmoszko, Central Connecticut State University, USA

\begin{abstract}
In sustaining long-term profitability, organizations must be lean and agile and must effectively be responsive to the opportunities and threats in the environment. This article introduces a strategic framework for crafting value proposition creation with the underlying integrated components of human capital, information capital and change management, resulting in long term profitability for the organization.
\end{abstract}

Keywords: Alignment of I.T., strategic management, value proposition, enterprise strategy

\section{THE GLOBAL NETWORK ECONOMY}

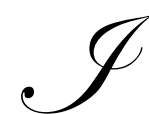

narguably, we are now in the global network economy. This paradigm shift and transformation from the data, information, and knowledge economy has gradually taken place since the $20^{\text {th }}$ century. The global network economy is made possible by the advances of telecommunications and information technology infrastructure and the decreasing cost of computer hardware production and software development. Equally important is the advancement in computing power and its devices, which is widely available and coupled with the low cost as indicated by Moore's "Law".

The availability and accessibility of these infrastructures and technology only continue to infiltrate in a global scale. In this global network economy, technology and knowledge become the core of sustaining wealth and value to the stakeholders. As a result, it is unrealistic for any firms to ignore the importance of information capital, and human capital as a means to sustain growth in this global competitive environment in the realm of e-business.

Applegate, 2007 stated that some academicians and business futurists would agree that the traditional organizational designs would be inadequate to cope with in the turbulent and increasing network world. "The characteristics of a global network economy could be summarized as agile, innovative and entrepreneurial. These do not compromise efficiency, power and reach that come with size and scale" (p.57). Most firms now are increasingly tapping into the extended network of partners to achieve higher economies of scale and power while creating higher value proposition demanded in the global environment. E-Business has become a critical factor for competitiveness and productivity growth.

As such, firms are now faced with the challenges in creating 1) a lean and agile enterprise influenced by the alignment of the enterprise with the environment and 2) the strategy chosen to quickly and effectively respond to opportunity and threats. In doing so, the alignment can only be effective by identifying the new capabilities that are needed to build a powerful and fluid business network. This paper provides the core of the needed capabilities and how it relates to an enterprise strategy to create sustainable value.

\section{CAPABILITIES TO SUSTAIN AN ENTERPRISE STRATEGY}

As stated earlier, the identification of capabilities becomes crucial in designing an agile and innovative enterprise. Two of the most profound capabilities in a global network economy are information capital and human capital. 


\section{Information Capital (IC) and Information and Communication Technologies (ICT)}

The terms IC and ICT are quite distinct by themselves. ICT is better known to the rest of the world due to the European Commission and The United Nations urgency in promoting ICT for development in the areas of education, health care, government, business, etc. On the other hand, Information Capital (IC) comprises the necessary applications, software systems and technology infrastructure which an organization needs to integrate into its business processes. In response to the global network economy and in e-business competitiveness, information capital and information and communication technologies (ICT) are regarded as the foundation for competitiveness in the new organizational model and design. Both terms are defined as follows:

1. ICT (Information and Communications Technology - or technologies) is an umbrella term that includes any communication device or application, encompassing: radio, television, cellular phones, computer and network hardware and software, satellite systems and so on, as well as the various services and applications associated with them, such as videoconferencing and distance learning. (Dice, 2004)

2. IC (Information Capital) is broken into two distinct parts; 1) "IC Applications is a package of information, knowledge, and technology required to support a business process. Within IC applications lay the transaction processing applications and business analytic applications"; 2) Technology Infrastructure, which is where the portfolio of IC Applications is supported. "Technology infrastructure includes such items as centralized computer systems, the desktop computing desktop, the corporate data warehouse, voice and data networks, help-desk support, and applications development." (Norton, (2002), pg.4)

From the definition above, ICT emphasizes the urgency for communication technologies to meet global competitiveness and to minimize digital divide, especially in the less developed countries. Many researchers have studied ICT at a macro-level of economic and societal development around the world; Trinidad and Tobago (Franklin, 2007), Asia-Pacific (Chacko \& Harris, 2006), Kenya (Migiro, 2006), Piedmont, Italy (Pollone \& Occelli, 2006), less developed countries (LDCs) (Li, 2005), Romania (Gurau, 2005), and The Netherlands (Drewe, et al, 2003). Based on these literatures, developing countries have the potential to achieve rapid and sustainable growth in economic and social development by developing ICT, therefore, enabling small and medium enterprises (SMEs) to conduct business in the global network economy. Furthermore, an ICT infrastructure enabled the deployment of extended network partners that is crucial in the global network economy.

At a closer look, Information Capital (IC) would assume that ICT is already in place within the macro level of economic development within its geographical boundary. The communication technologies infrastructure would then enable IC to sufficiently suffice at the micro (enterprise) level. Information Capital, therefore, must be supported by ICT infrastructure for economic development within a specific country. In short, both IC, and ICT refer to the necessity and implementation of technologies to sustain development, exchanging information, and to boost operational efficiencies in a global context. Kaplan \& Norton (2004) stated that Information Capital is the raw material for creating value in an enterprise in the new economy. The two key components of IC are i) Technology infrastructure, and ii) Information Capital applications.

Figure1 shows an adaption of Norton (2002) taxonomy of information capital with IC applications and the technology infrastructure that supports them. As a result, this paper focuses at the enterprise-level, that is, within the context of an enterprise's adoption of IC applications and technologies as a strategic initiative, either at large global firms or SMEs.

\section{Human Capital (HC)}

Stewart (1997) stated that human capital (HC) refers to "the capabilities of individuals required to provide solutions to customers" (pg. 7). Many researchers have studied human capital, and confirmed HC as the most significant asset in enterprises. (Baron \& Armstrong, 2007; Benowitz, 2008; de Castro \& Saez, 2008; Whitaker, 2007; Schiemann, 2007). CIC (2003) defined human capital as that which makes reference to the tacit or explicit knowledge which people possess, as well as their ability to generate it, which is useful for the mission of the enterprise and includes values and attitudes, aptitudes and know-how. 
From another perspective, "Human capital Theory (Becker, 1964; 1993) posits that individuals with more or highly-quality perform better at executing relevant tasks, so human capital pertains to individual knowledge and abilities that allow for changes in action and economic growth. Human capital may be developed through formal training and education aimed at updating and renewing an individual's capabilities in order to do well in society," (Nakhata, 2007, pg. 63)

From a HC strategic standpoint, Selvarajan, et al., (2007) research supported that human capital philosophy mediates innovativeness in the relationships between firm strategy, industry environment and firm performance. Since individuals possess information and knowledge, and play a pivotal role in wealth and growth of the firm, how can a firm recruit, and retain these individual? With a group of colleagues in a global management consulting firm at Accenture, Cheese, et al (2008), examine the shift from manual work toward knowledge-based economies and the resulting competition for talent between enterprises and between countries, and discuss reasons and ways for organizational leaders to multiply the value of talent in every part of their enterprise, embrace diversity to gain competitive advantage from the proliferation and complexity of talent markets, invest in learning and skills development in a more focused way, build engagement in all of the organization's talent, and share responsibility for talent multiplication throughout the enterprise. Engagement is discussed in great detail with the six Cs that drives engagement; content (Do I enjoy what I do?), coping, (How am I supported?), compensation (Am I fairly rewarded?), congruence (Do values align?), community (Is it socially rewarding?), and career (Where am I going?). They concluded that the ability to discover, develop, deploy, motivate and energize human talent is the most valuable strategy in any enterprise.

Norton (2002) further stated that "Individuals possess information and knowledge; when the organization captures and packages them for use by others, they become capital". (pg. 3) These information and knowledge are housed within the information capital, such as systems, databases and if used properly, these intangible values of IC can create tangible assets. Therefore, to sustain the talent multiplication effort, HR systems should be implemented to consolidate and forms a solid base of data and information that provide tangible values to the firm. HR Systems that includes the acquisition and storage of information and skills entails internal wealth creation in human capital management. This information and data, when collected, serves as a means to strengthen the initiative on sharing and collaboration within, thus resulting in a knowledge-based firm.

\section{ENTERPRISE STRATEGY}

An enterprise without a good strategic plan is like a ship in an ocean without a plan for navigating through turbulence and point of course. Strategy is a matter of survival. It must be focused on profitability of an enterprise rather than just growth, and by offering a unique value proposition. Porter (2001) stated that "Strategy goes far beyond the pursuits of best practices. It involves the configuration of a tailored value chain - the series of activities required to produce and deliver a product or service - that enables a company to offer unique value" (pg. 72). On a different perspective, Henderson and Venkatraman (1993) viewed strategy as involving both formulation (decisions pertaining to competitive, product-market choices) and implementation (choices that pertains to the structure and capabilities of the firm to execute its product-market choices). Lauden and Traver (2009, pg 104) defines strategy as "a set of plans for achieving superior long term returns on the capital invested in a business firm. An organizational strategy is therefore a plan for making profits in a competitive environment in the long term. Profit is simply the difference of the price a firm is able to charge for its product and the cost in producing and distributing the goods. Profit represents economic value. Economic value is created anytime customer is willing to pay more for a product than it cost to produce."

In a similar context, Porter (2001) stated that many organizations have competed in ways that violates nearly every percept of good strategy. "Rather than focus on profits, they have sought to maximize revenue and market share at all costs, pursuing customers indiscriminately through discounting, giveaways, promotions, channel incentives, and heavy advertising" (pg. 72).

As stated earlier, an enterprise strategy is a long-term plan for making profits, which is a result of achieving value proposition creation. However, achieving the ultimate value that are deemed most important from a customer perspective can deter or influence by the external environment and internal processes. A strategy map, therefore, 
must be drawn to guide and manage the flow of internal processes or changes needed to achieve the long term goal. This does not compromise the need to effectively respond to change due to external environmental changes in a lean and agile organizational climate.

Norton (2001) introduced a shared model strategy map that encompasses leadership team from both business and I.T. known as the Balanced Scorecard strategy map. The strategy map cuts across functional areas (by minimizing isolation), identify the key internal processes and capabilities that include $\mathrm{HC}$ and IC that align with the ultimate goal of value creation in the long term. The strategy map provides a framework for describing strategic priorities. The IC applications and $\mathrm{HC}$ portfolios should be aligned to the strategy map through the identification of each set of priorities. Figure 2 shows the framework of an integrated strategy plan to support the strategic initiatives.

The underlying foundation of the strategy map encompasses the learning and growth perspective. This stage requires an analysis of the current situation of the firm and the capabilities that it needs to carefully align with its strategic programs. With succinct alignment of its two components (human capital and information capital), these would result in achieving a higher success of value proposition creation that ultimately results in achieving its profitability.

Figure 1. A Taxonomy of Information Capital

(Adapted \& Revised from Norton, (2002) pg. 5)

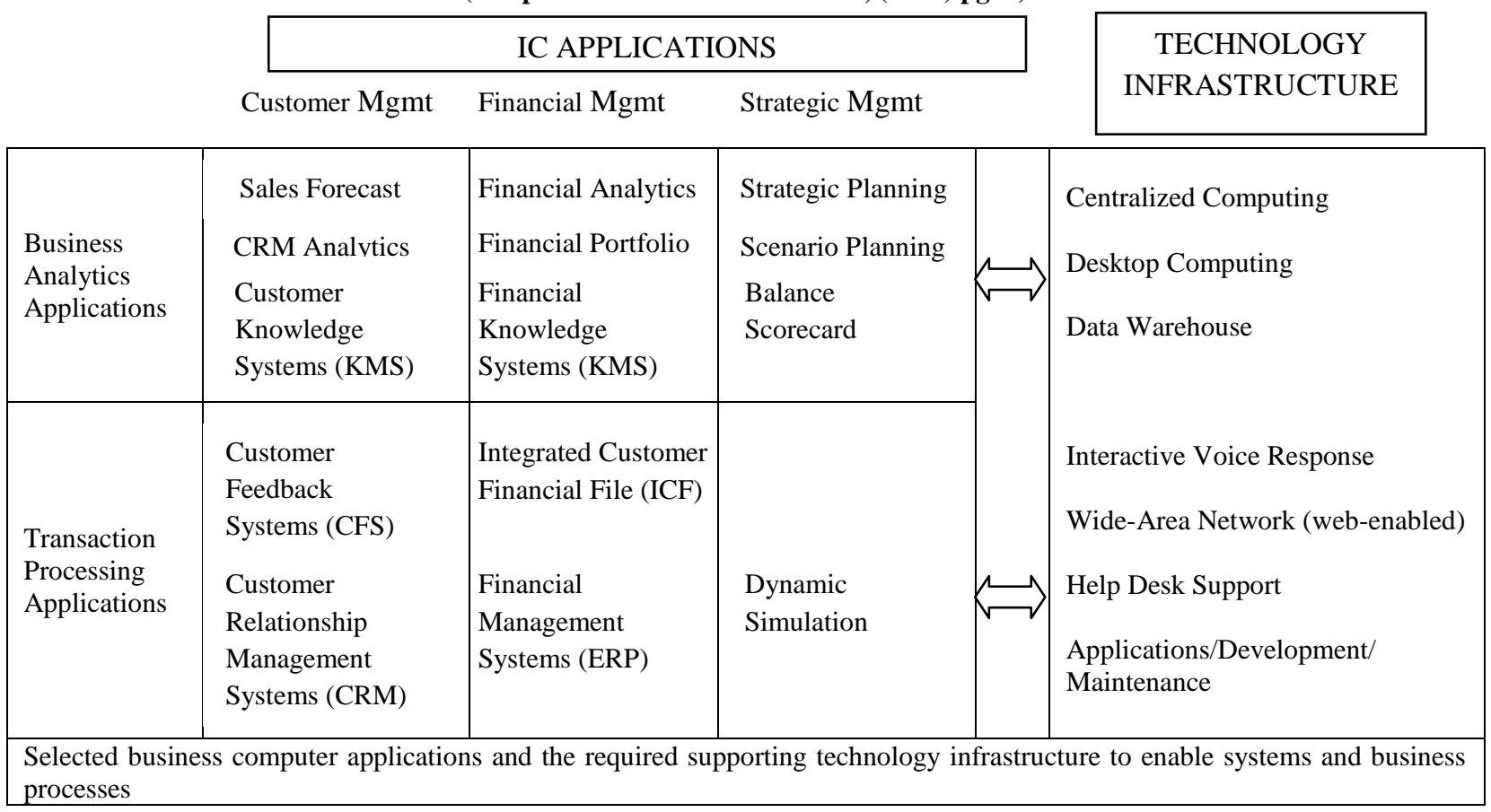

In major transformation of any organizations, the conventional focus of attention has been on strategic and tactical plans. However, to fully implement a successful transformation, its third component, change management (Figure 2), requires creation of a new stage of business, which naturally requires leadership. A paralyzed decisionmaking process is a symptom of having too many managers, and not enough leaders (Kotter, 1995). Launching a continuous improvement initiative and transformation of change requires an intimate understanding of the human side of change management - "the alignment of the company's culture, values, people, and behaviors. Plans themselves do not capture value; value is realized only through the sustained, collective actions of the thousandsperhaps the tens of thousands - of employees who are responsible for designing, executing, and living with the change environment.” (J. Jones, ect al. 2004, pg 2). 
It is undeniably understood that the transformation of change is inevitable in the renewal of business processes to achieve organizational strategic goals. These transformational initiatives, with the tight integration of information capital and the knowledge of human capital, work cohesively in sustaining a guided and focused plan of action.

Figure 2. Framework for Aligning Intangible Assets with the Strategy (with IC Portfolio)

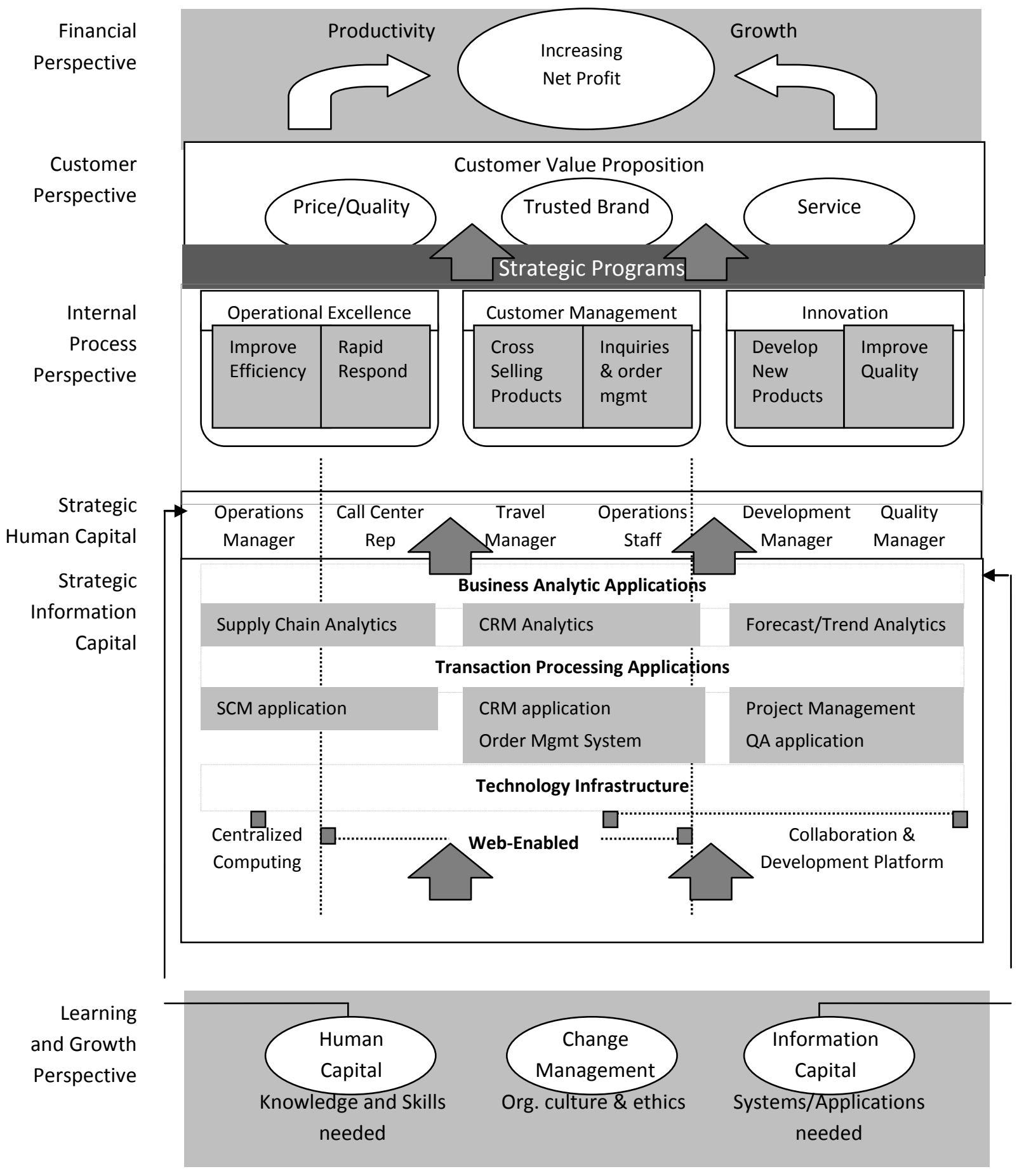


A strategic framework towards value proposition creation which aligns to the strategic programs in response to the organizational strategy

\section{CONCLUSIONS AND RECOMMENDATIONS}

This article has provided the framework for value proposition creation through the alignment of human capital and information capital, resulting in profitability as a strategic initiative. The crafting of an enterprise strategy begins with the understanding of the current environment and to formulate a strategic plan to sustain profitability in the long-term.

As illustrated in the framework (Figure 2), the strategic information capital portfolio may change over time, due to the advancement and accessibility of technologies, but not drastically. The framework can be adapted in many forms and variations. It can be implemented in accordance to the current organizational internal and external environments, however, the framework remains an integrated plan and guide to sustain long term profitability for organizations in the global network economy.

\section{AUTHOR INFORMATION}

Dr. Leslie Leong is currently a senior lecturer at the Business School, University of Greenwich, London. She was previously a full professor at Central Connecticut State University from 2001 to 2009. Prof. Leong has worked for over eleven years at the private sector in various I.T. positions prior to joining CCSU. Her research interest includes e-Business and management strategies, and information and communications technology (ICT) in the global economy.

Dr. A. Tomasz Jarmoszko is Associate Professor in MIS at Central Connecticut State University, USA. His primary teaching areas are systems analysis and design and data communications and networking. Prior to joining CCSU, Dr. Jarmoszko was Manager for Strategic Planning a major mobile communications company in Central Europe. His current research interests include information systems curriculum, mobile information systems, aligning knowledge management with the strategy process and strategic management in the communications industry.

\section{REFERENCES}

1. Applegate, L.M., Austin, R.D., \& McFarlan, F.W. (2007). Corporate Information Strategy and Management, $2^{\text {nd }}$ edition, N.Y.: McGraw Hill/Irwin Publishing

2. Baron, A. \& Armstrong, M. (2007). Human Capital Management: Achieving Added Value Through People, U.K.: Kogan Page Publisher

3. Becker, G.S. (1964). Human Capital: A Theoretical and Empirical Analysis, with special reference to education, NY: Columbia University Press

4. Becker, G.S. (1993). Human Capital: A Theoretical and Empirical Analysis. Chicago: University of Chicago Press.

5. Beheshti, H.M., Salehi-Sangari, E. \& Engstrom, A. (2006). Competitive Advantage with e-Business: A Survey of Large American and Swedish Firms, Competitiveness Review, 16 (2), 150-157

6. $\quad$ Benowitz, S. (2008). Human Capital-The Most Critical Assets, Public Manager, 37 (1), 29-33

7. Chacko, J.G. \& Harris, G. (2006). Information and Communication Technology and Small, Medium, and Micro Enterprises in Asia-Pacific_-Size Does Matter, Information Technology for Development, 12 (2), 175-177

8. Cheese, P., Thomas, R.J., \& Craig, E. (2008). The Talent Powered Organization: strategies for globalization, talent management and high performance, U.K.: Kogan Page Publisher

9. CIC (2003), Modelo Intellectus: Medición y Gestiơn del Capital Intelectual, Centro de Investigación sobre la Sociedad del Conocimiento (CIC), Madrid

10. de Castro, G.M. \& Saez, P.L. (2008). Intellectual Capital in High-Tech Firms, Journal of Intellectual Capital, 9 (1), 25-36 
11. Dice (2004). Available from : http://searchciomidmarket.techtarget.com/sDefinition $/ 0$, ,sid183 gci928405,00.html\#

12. Drewe, P., Fernandez-Maldonado, A.M., \& Hulsbergen, E. (2003). Battling Urban Deprivation: ICT Strategies in the Netherlands and Europe, Journal of Urban Technology, 10 (1), 23-37

13. Franklin, M.. (2007). The Pursuit of Development and Poverty Reduction through Information and Communication Technology (ICT) in Trinidad and Tobago, Journal of Eastern Caribbean Studies, 32 (2), 23-49

14. Gurau, G. (2005). ICT Strategies for Development: Implementing Multichannel Banking in Romania, Information Technology for Development, 11 (4), 343-362

15. Henderson, J.C. \& Venkatraman, N. (1993). Strategic Alignment: Leveraging Information Technology for Transforming Organization, IBM Systems Journal, 32, (1), 472-484

16. Jones, J., Aquirre, D., and Calderone, M. (2004). 10 Principles of Change Management, Resilience report, Strategy+Business, Booz \& Company Publishers

17. Kaplan, R., \& Norton, D. (2004). Strategy Maps, Converting Intangible Assets into Tangible Outcomes, Boston: Harvard Business School Press

18. Kotter, J.P. (1995). Leading Change: Why Transformation Efforts Fail, Harvard Business Review

19. Li, S. (2005). The Impact of Information and Communication Technology on Relation-based Governance Systems, Information Technology for Development, 11 (2), 105-122

20. Lauden, K. and Traver, C.G. (2009). E-Commerce, Prentice-Hall, ISBN: 10-0136007112

21. Migiro, S.O. (2006). Diffusion of ICTs and E-Commerce Adoption in Manufacturing in SMEs in Kenya, South African Journal of Library and Information Science, 72 (1), 35-44

22. Nakhata, C. (2007). The Effects of Human Capital and Entrepreneurial Competencies on the Career Success of SME Entrepreneurs in Thailand, The Business Review, 9 (1), 62-69

23. Norton, D.P. (2002). Creating Strategic Alignment and Readiness for I.T. Balanced Scorecard Report, Harvard Business School Publishing Corporation, 3-6

24. Pollone, M., \& Occelli, S. (2006). Information and Communication Technologies and Regional Development: The Case of Piedmont, Italy, Journal of Urban Technology, 13 (3). 93-118

25. Porter, M. (2001). Strategy and the Internet. Harvard Business Review, Harvard Business School Publishing Corporation, 63-78

26. Selvaraian, T.T., Ramamoorthy, N., Flood, P.C., and Guthrie, J.P. (2007). The role of human capital philosophy in promoting firm innovativeness and performance,: test of a causal model, The International Journal of Human Resource Management, 18 (8), 1456

27. Schiemann, W. (2007). Measuring and Managing the ROI of Human Capital, Cost Management, 21 (4), 515

28. Stewart, T. (1997). Intellectual Capital: The New Wealth of Organizations. Brealy Publishing

29. Whitaker, D. (2007). Are Sustainability and Human Capital Management So Very Different? Personnel Today, Nov. 6, pg 17 


\section{NOTES}

